\title{
Effect of Silica Nanoparticles and BTCA on Physical Properties of Cotton Fabrics
}

\author{
Gobi Nallathambi $^{\mathrm{a} *}$, Thangavelu Ramachandran ${ }^{\mathrm{b}}, V_{\text {Venkatachalam Rajendran }}^{\mathrm{c}}$, Rajagoundar Palanivelu ${ }^{\mathrm{d}}$ \\ ${ }^{a}$ Department of Textile Technology, Anna University, Chennai, 6000025, Tamilnadu, India \\ ${ }^{\mathrm{b}}$ Karpagam Institute of Technology, Coimbatore, Tamilnadu, India \\ ${ }^{\mathrm{c}}$ Centre for Nano Science and Technology \\ ${ }^{\mathrm{d} D e p a r t m e n t}$ of Chemistry, K.S. Rangasamy College of Technology, \\ Tiruchengode, Tamilnadu, India
}

Received: May 7, 2011; Revised: October 4, 2011

\begin{abstract}
Silica nanoparticles particles were synthesized from rice hulls and characterized. The particles were found to be amorphous in nature, ranging in size from 50 to $100 \mathrm{~nm}$. The concentration of silica nanoparticles, $\mathrm{pH}$ and curing time were taken as independent variables to design the experiment. Box-Behnken method has been used to derive the experimental plan and fifteen experiments were conducted. Regression equations have been formed with the dependent and independent variables and the results of all possible combinations have been derived. The combination of optimized concentration of BTCA and SHP were used as crosslinking agent and catalyst respectively and silica nano particles were used to enhance the physical properties of the cotton fabric. The effect of $\mathrm{pH}$ and curing time on physical properties were analysed by FTIR studies. By ranking method the best combination of process parameters were identified. From this study, it was observed that higher concentration of silica nanoparticles with BTCA improve the crease recovery angle and tensile strength. FTIR studies revealed that the increase of $\mathrm{pH}$ and curing time increases the ester carbonyl band intensity ratio.
\end{abstract}

Keywords: silica nanoparticles, BTCA, box Behnken method, crease recovery

\section{Introduction}

Finishing is a process step to add value to the textile product. It is classified into two categories such as physical finishes and chemical finishes. Functional finishes are one of the chemical finishes incorporated into the textile materials to enhance the functional and comfort properties ${ }^{1}$. Nanotechnology has the potential to create new bulk materials with new bulk properties in textile coating and finishing ${ }^{2}$. Nano particles can provide high durability for fabrics, because of its larger surface area-to-volume ratio and high surface energy. These can present better affinity for fabrics and leading to an increase in durability without affecting their breathability or hand feel ${ }^{3-5}$.

Cotton is poor in crease resistance due to its free hydroxyl groups. To enhance the crease recovery property of cotton, the free hydroxyl groups are either removed or cross linked by applying formaldehyde and non formaldehyde based cross linking agents. The hazardous nature of the formaldehyde cross linking agents is replaced by non formaldehyde cross linking agents such as citric acid and BTCA (1,2,3,4-butanetetracarboxylic acid). The decrease of whiteness index of cotton fabric treated with citric acid tends to increase the usage of BTCA.

The mechanism of cross linking of cellulose with polycarboxylic acids is given in Figure 1. The mechanism of polycarboxylic acids is carried out in two steps by cellulose esterification. In the first step the formation of a cyclic anhydride intermediate by the dehydration of two carboxyl groups is carried out. In the second step the ester crosslinks are formed by the reaction between the anhydride with cellulose $^{6}$. Polycarboxylic acid esterifies cellulose through the formation of a five-membered cyclic anhydride intermediate by the dehydration of two adjacent carboxyl groups ${ }^{7}$. The formation of cyclic anhydrides at lower temperatures is slow without catalyst, but the catalyst sodiumhypophosphite (SHP) accelerates the cyclic anhydride process $^{8,9}$. High curing temperature and high BTCA concentration reduce the tensile strength and increase the crease recovery angle ${ }^{10}$. The whiteness index of the treated fabrics seems to decrease as the concentration of cross linkers increases ${ }^{11-15}$. The quantity of the cyclic anhydride intermediate formed in a cotton fabric increased as the $\mathrm{pH}$ of a finish bath was reduced from 4.5 to $1.5^{[16,17]}$.

The metal oxide nanoparticles such as $\mathrm{SiO}_{2}, \mathrm{TiO}_{2}, \mathrm{ZnO}$ and $\mathrm{Fe}_{2} \mathrm{O}_{3}$ are used as UV blocking agents, antimicrobial agents, water repellents etc. ${ }^{18-20}$.

The thermodynamic affinity of fibres form noncovalent interactions such as dipolar-dipolar and hydrogen bond, should be the key interactions for the adhesion of silica particles. The $\mathrm{Si}-\mathrm{O}-$ cellulose covalent bonds in coated cellulose fabrics, make less contribution towards the adhesion of particles. Moreover, the cellulose in cotton $(\sim 98 \%)$ fabric plays a decisive role in the intensity of covalent bond between the cellulosic hydroxyl group and-Si-OH in silica particles ${ }^{21,22}$. The bond formation can improve the crease resistance property of the cotton fabrics. The crease recovery finishing process with DMEU, tetraethoxysilane (TEOS) and isoproponal at various volumes improved the crease resistance and tensile strength ${ }^{23}$.

In most of the techniques to synthesis the nano silica, the base material is taken from the chemically available precursors such as tetraethoxysilane (TEOS) by sol-gel method ${ }^{23}$. But in the case of thermal degradation, the source material taken from natural resource such as rice hulls is the simplest and cost effective method for large scale production of silica nano particles ${ }^{24}$. In this research work, the synthesized silica nanoparticles are coated on the surface of the fabric with BTCA and SHP to analyse the crease recovery and other physical properties of the fabric and also the process parameters are optimized. 


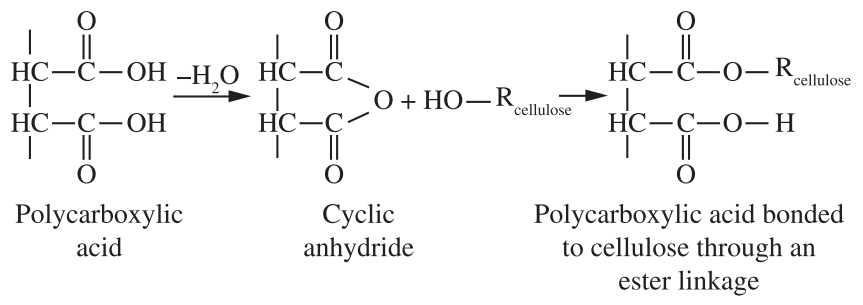

Figure 1. The mechanism of cross linking of cellulose and polycarboxylic acids.

\section{Experimental}

Amorphous silica nanoparticles were prepared by thermal degradation method from natural resource of rice hull. The rice hulls were rinsed, dried and aged at $80^{\circ} \mathrm{C}$ for 1 hour and converted to micro particles. The particles were refluxed with $10 \% \mathrm{HCl}$ for 30 minutes and dried at $80{ }^{\circ} \mathrm{C}$. The residue was kept in a muffle furnace at $750{ }^{\circ} \mathrm{C}$ for 3 hours to convert nano particles. The synthesized silica nanoparticles were characterized by X-Ray Diffractometer (LabX XRD-6000) to find out the nature of the particles. Scanning Electron Microscope (HITACHI S-3400 SEM) and High Resolution Transmission Electron Microscope (FEI Quanta FEG 200) are used to find out the size of the silica nanoparticles.

Three levels and three variables were selected to design the experiment by Box-Behnken method and it is given in Table 1. Fifteen different combinations of experiments were derived and conducted, each combination has different process parameters such as concentration of silica nanoparticles, $\mathrm{pH}$ and curing time and it is given in Table 2. In each experiment, the pad solution contains different concentration of silica nanoparticles (1, 1.5 and 2\%), 1,2,3,4-butanetetracarboxylic acid (BTCA) $6.5 \%$ and sodium hypophosphite (SHP) (both from Sigma-Aldrich) $4.5 \%$ with a fabric softener of silicone emulsion( $1 \%$, Finox HSS), acrylic binder (Texacryl binder ELT) and wetting agent $(0.1 \%$, Lissapol-N). The $\mathrm{pH}(1.52,2.39$ and 3.01) of the each experiment varied as per the experimental plan. The prepared solution has been coated on the surface of cotton fabric (134 ends.inch ${ }^{-1}, 64$ picks.inch $^{-1}, 120$ g.m ${ }^{-2}$, $40 \times 40$ seconds count and plain weave) to impart crease recovery property by pneumatic padding mangle with the material-to-liquor ratio of 1:5 and $100 \%$ wet pickup was maintained for all experiments. Then, it was squeezed and dried at $85{ }^{\circ} \mathrm{C}$ for 5 minutes and subsequently cured at $180{ }^{\circ} \mathrm{C}$ at different curing intervals of 60,120 and 180 seconds. The cured fabrics were treated with $0.1 \mathrm{M}$ $\mathrm{NaOH}$ solution at room temperature for two minutes to convert the free carboxyl groups to carboxylate, rinsed with cold water and dried at $80{ }^{\circ} \mathrm{C}$ for 5 minutes.

A quadratic polynome was used to analyze the relationship of each response with the three independent variables. The multiple polynomial regression equation was used to derive the regression co-efficients to analyse the fabric properties and is given in Equation 1.

$$
\mathrm{Y}=\mathrm{b}_{0}+\sum_{\mathrm{i}=1}^{3} \mathrm{~b}_{\mathrm{i}} \mathrm{x}_{\mathrm{i}} \sum_{\substack{\mathrm{i}=1 \\ \mathrm{i}<\mathrm{j}}}^{3} \mathrm{~b}_{\mathrm{ij}} \mathrm{x}_{\mathrm{i}}^{2}+\sum_{\mathrm{i}=1}^{3} \mathrm{~b}_{\mathrm{ij}} \mathrm{x}_{\mathrm{i}} \mathrm{x}_{\mathrm{i}}
$$

where $b_{0}, b_{i}, b_{i i}$ and $b_{i j}$ are the co-efficients of the regression equations, $\mathrm{i}, \mathrm{j}$ are integers and $\mathrm{Y}$ is the response of the dependent variable.

The physical properties of treated and untreated fabrics were tested as per ASTM test methods such as crease recovery angle (D 1295-67), tensile strength (D 5035-95), tearing strength (D 1424-96), weight loss due to abrasion (D 4966-98), air permeability (D 737-96), flexural rigidity (D 1388-08) and whiteness index (E 313-98) and the results are given in Table 2 .
Table 1. Experimental plan of process parameters with different levels for silica nanoparticles and BTCA coating process.

\begin{tabular}{ccccc}
\hline Variables & Process parameters & \multicolumn{3}{c}{ Levels } \\
\cline { 3 - 5 } & & -1 & 0 & +1 \\
\hline $\mathrm{X}_{1}$ & $\begin{array}{c}\text { Concentration of silica } \\
\text { nanoparticles (\%) }\end{array}$ & 1 & 1.5 & 2 \\
\hline $\mathrm{X}_{2}$ & $\mathrm{pH}$ & 1.52 & 2.39 & 3.01 \\
\hline $\mathrm{X}_{3}$ & Curing time in seconds & 60 & 120 & 180 \\
\hline
\end{tabular}

\subsection{Quality factor and ranking method}

Quality factor has been derived for fabric properties which consist of the importance of each property given by this experiment. Higher priority has been given to crease recovery angle and surface coating processes generally reduce the strength behavior and permeability of the fabric. Hence it is considered next to crease recovery respectively. Equation 2 has been used to calculate the quality factor. The quality factor has been ranked and it is given in Table 4 .

$\mathrm{X}=\mathrm{a} 0.3+\mathrm{b} 0.2+\mathrm{c} 0.15+\mathrm{d} 0.1+\mathrm{e} 0.1+\mathrm{f} 0.05+\mathrm{g} 0.1$

Where $\mathrm{X}=$ quality factor

- $\mathrm{a}=$ crease recovery angle in degrees

- $\mathrm{b}=$ whiteness index

- $\mathrm{c}=$ tensile strength in $\mathrm{kg}$

- $\mathrm{d}=$ tearing strength in $\mathrm{g}$

- $\mathrm{e}=$ flexural rigidity in $\mathrm{g} \cdot \mathrm{cm}^{-1}$

- $\mathrm{f}=$ weight loss due to abrasion in $\mathrm{g}$

- $\mathrm{g}=$ air permeability in $\mathrm{cm}^{3} \cdot \mathrm{cm}^{-2} / \mathrm{s}$

\section{Results}

\subsection{Characterization of silica nanoparticles}

The synthesized silica nanoparticles were characterized by X-ray Diffractometer (XRD) using $\mathrm{CuK}_{\alpha}(\lambda=1.54 \AA$ ) as a radiation source. The XRD patterns of the silica nanoparticles obtained from rice hulls is shown in Figure 2. The powder diffraction pattern indicates a broad peak at $2 \theta=22^{\circ}$, which reveals the amorphous nature of the silica nanoparticles. Further, the XRD pattern confirms the absence of any ordered crystalline structure.

High Resolution Transmission Electron Microscope (HRTEM) was used to characterize the particle size and the image of nano particles are shown in Figure 3. It shows that the particles size is below $100 \mathrm{~nm}$.

\subsection{Analysis of physical properties}

The physical properties of the coated and uncoated fabrics were analysed and are given in Table 1. Regression equations were derived for each property and are given in Table 3 . The results of all possible combinations of process parameters have been derived and are given in Table 4.

\subsection{FTIR analysis of coated fabric}

The infra red spectroscopy data demonstrated that ester cross linkages in a finished cotton can be examined and evaluated on a semiquantitative basis by measuring the ester band intensity and carbonyl band intensity ratio (ester/carboxylate). The carbonyl band intensity ratio (ester/ carboxylate) is a function of the average number of ester groups formed for each BTCA molecule, so it represents the effectiveness of this bonded BTCA molecule as a crosslinking agent ${ }^{17}$. 
Table 2. Properties of untreated, silica nanoparticles and BTCA coated samples.

\begin{tabular}{|c|c|c|c|c|c|c|c|c|c|c|}
\hline \multirow{2}{*}{$\begin{array}{c}\text { Sample } \\
\text { No. }\end{array}$} & \multicolumn{10}{|c|}{ Process parameters } \\
\hline & $\begin{array}{c}\text { Nano } \\
\text { Silica \% }\end{array}$ & $\mathrm{pH}$ & $\begin{array}{l}\text { Curing } \\
\text { time in } \\
\text { seconds }\end{array}$ & $\begin{array}{c}\text { Crease } \\
\text { recovery angle } \\
(\mathrm{w}+\mathrm{f})\end{array}$ & $\begin{array}{l}\text { Whiteness } \\
\text { index }\end{array}$ & $\begin{array}{l}\text { Tensile } \\
\text { strength } \\
\text { in kg }\end{array}$ & $\begin{array}{l}\text { Tear } \\
\text { strength } \\
\text { in } \mathrm{g}\end{array}$ & $\begin{array}{c}\text { Flexural } \\
\text { rigidity } \\
\left(\mathrm{mg} \cdot \mathrm{cm}^{-1}\right)\end{array}$ & $\begin{array}{c}\text { Weight loss } \\
\text { (\%) due to } \\
\text { abrasion }\end{array}$ & $\begin{array}{l}\text { Air permeability } \\
\left(\mathrm{cm}^{3} \cdot \mathrm{cm}^{-2} / \mathrm{s}\right)\end{array}$ \\
\hline U1 & - & - & - & 94 & 82.2 & 57.6 & 1312 & 1622 & 1.49 & 26.25 \\
\hline $\mathrm{T} 1$ & 1 & 1.52 & 120 & 180 & 71.5 & 63.4 & 1314 & 1822 & 2.93 & 26.20 \\
\hline $\mathrm{T} 2$ & 2 & 1.52 & 120 & 200 & 68.2 & 66.3 & 1386 & 1891 & 2.58 & 21.30 \\
\hline $\mathrm{T} 3$ & 1.5 & 1.52 & 180 & 196 & 69.1 & 62.5 & 1374 & 1838 & 2.64 & 24.30 \\
\hline $\mathrm{T} 4$ & 1.5 & 1.52 & 60 & 192 & 70.2 & 64.7 & 1365 & 1832 & 2.50 & 24.89 \\
\hline T5 & 2 & 2.39 & 180 & 221 & 67.2 & 71.2 & 1461 & 1916 & 2.05 & 21.90 \\
\hline T6 & 1 & 2.39 & 180 & 194 & 70.5 & 65.4 & 1340 & 1820 & 2.16 & 26.30 \\
\hline $\mathrm{T} 7$ & 2 & 2.39 & 60 & 218 & 68.5 & 69.3 & 1442 & 1902 & 1.95 & 21.78 \\
\hline $\mathrm{T} 8$ & 1 & 2.39 & 60 & 189 & 72.3 & 64.2 & 1335 & 1826 & 1.98 & 26.80 \\
\hline T9 & 1.5 & 3.01 & 60 & 212 & 72.5 & 68.5 & 1415 & 1843 & 1.64 & 24.30 \\
\hline $\mathrm{T} 10$ & 1.5 & 3.01 & 180 & 215 & 71.8 & 65.2 & 1424 & 1876 & 2.48 & 24.60 \\
\hline $\mathrm{T} 11$ & 2 & 3.01 & 120 & 225 & 70.5 & 73.5 & 1485 & 1920 & 1.84 & 21.90 \\
\hline $\mathrm{T} 12$ & 1 & 3.01 & 120 & 201 & 72.5 & 67.1 & 1398 & 1824 & 1.74 & 26.30 \\
\hline $\mathrm{T} 13$ & 1.5 & 2.39 & 120 & 205 & 69.8 & 67.8 & 1407 & 1856 & 1.82 & 24.90 \\
\hline $\mathrm{T} 14$ & 1.5 & 2.39 & 120 & 207 & 70.2 & 67.5 & 1405 & 1860 & 1.89 & 24.50 \\
\hline T15 & 1.5 & 2.39 & 120 & 205 & 70.1 & 67.4 & 1405 & 1859 & 1.85 & 24.80 \\
\hline
\end{tabular}

$\mathrm{U}$ - untreated, $\mathrm{T}$ - treated.

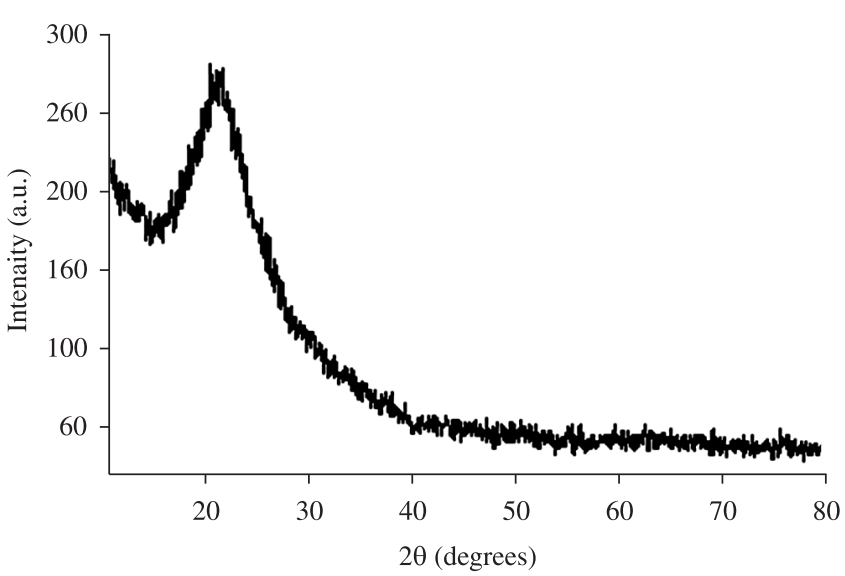

Figure 2. XRD pattern of silica nanoparticles.

Figure 4 shows the FTIR spectroscopy of silica nanoparticles and BTCA coated fabrics with different $\mathrm{pH}$ and curing time. From the figure it was observed that the carbonyl band at 1722 to $1735 \mathrm{~cm}^{-1}$ represents the carbonyl of ester while the band at 1577 to $1586 \mathrm{~cm}^{-1}$ and it represents the carbonyl of carboxylate ${ }^{17}$. The above two are the basic forms of the free carboxylic acids.

Table 5 shows that the values of ester carbonyl band intensity and carbonyl band intensity ratio. The values for the above are 0.516 to 0.545 and 0.619 to 0.636 respectively. By increasing the curing time from 60 to 180 seconds and the $\mathrm{pH}$ value of 1.52 to 3.01 with the BTCA concentration of $6.5 \%$, the ester carbonyl band intensity and carbonyl band intensity ratio were increased. Carboxyl is the predominant species in the BTCA solution when the $\mathrm{pH}$ ranges from 1.52 to 2.39 which is demonstrated by the intense

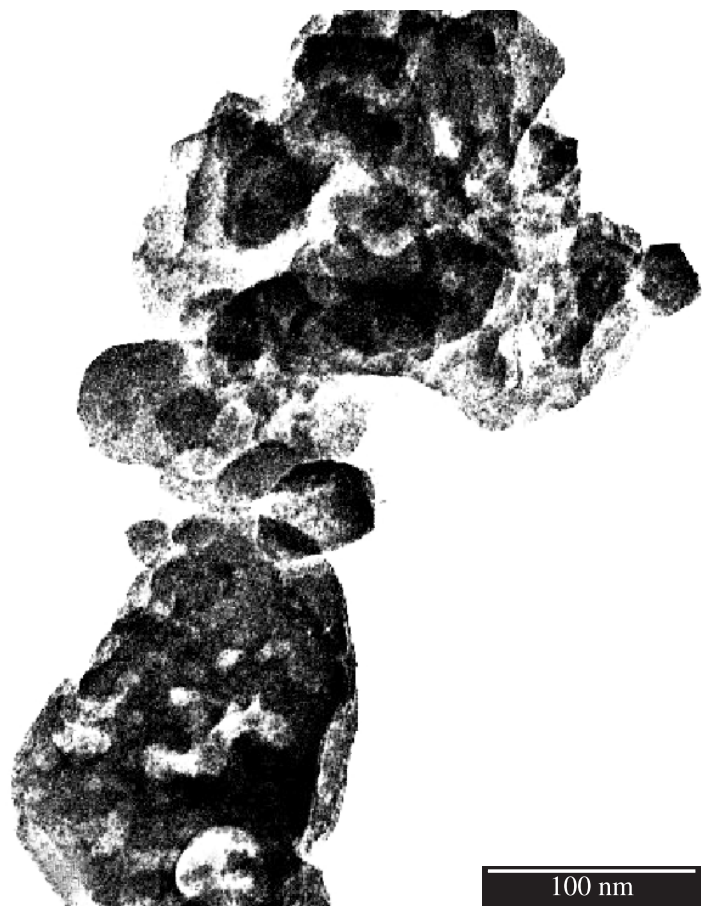

Figure 3. HR TEM image of silica nanoparticles.

carboxyl carbony band at $1725 \mathrm{~cm}^{-1[17]}$. The conversion of carbonyl to carboxylate reaches maximum when the $\mathrm{pH}$ of the BTCA solution is $3.01^{17}$. When the carbonyl band intensity ratio increases, the cross linking increases. It is evident that the crease recovery angle has been increased proportionally. Choosing the optimum $\mathrm{pH}$ range will reduce the quantity of BTCA for desirable fabric performance, thus reducing the cost of non formaldehyde agents ${ }^{17}$. 
Table 3. Regression equations for silica nanoparticles and BTCA coated fabric properties.

\begin{tabular}{|c|c|c|c|c|c|}
\hline S. No. & Property & Regression equation & $\mathrm{R}$ & $\mathrm{R}^{2}$ & F-ratio \\
\hline 1. & $\begin{array}{l}\text { Crease recovery } \\
\text { angle }\end{array}$ & $\begin{array}{c}Y=101.277 X_{1}+67.022 X_{2}+0.264 X_{3}-18.367 X_{1}^{2}-8.896 X_{2}^{2} \\
-4.110 X_{3}^{2}-0.0801 X_{1} X_{2}-0.045 X_{2} X_{3}\end{array}$ & 1.000 & 0.935 & 2572 \\
\hline 2. & Whiteness index & $\mathrm{Y}=72.462-3.008 \mathrm{X}_{1}-1.526 \mathrm{X}_{2}-0.010 \mathrm{X}_{3}$ & 0.897 & 0.805 & 15.17 \\
\hline 3. & Tensile strength & $\begin{aligned} Y= & 45.899 X_{1}+21.343 X_{2}+0.161 X_{3}-6.658 X_{1}^{2}-2.857 X_{2}^{2} \\
& -0.001 X_{3}^{2}-1.854 X_{1} X_{2}-0.029 X_{1} X_{3}-0.015 X_{2} X_{3}\end{aligned}$ & 0.999 & 0.722 & 1048 \\
\hline 4. & Tear strength & $\begin{array}{c}Y=761.826 X_{1}+458.910 X_{2}+3.031 X_{3}-151.203 X_{1}^{2}-60.028 X_{2}^{2} \\
\quad-0.005 X_{3}^{2}-56.395 X_{1} X_{2}-0.505 X_{1} X_{3}-0.385 X_{2} X_{3}\end{array}$ & 1.000 & 0.690 & 1135 \\
\hline 5 . & Weight loss & $\begin{array}{c}Y=3.839 X 1-1.048 X_{2}+0.012 X_{3}-0.832 X_{1}^{2}+0.184 X_{2}^{2} \\
-0.241 X_{1} X_{2}-0.006 X_{1} X_{3}+0.001 X_{2} X_{3}\end{array}$ & 0.987 & 0.539 & 49 \\
\hline 6. & Flexural rigidity & $Y=1683.152+86.75 X 1+15.997 X_{2}+0.074 X_{3}$ & 0.966 & 0.933 & 50.75 \\
\hline 7. & Air permeability & $\begin{array}{rl}Y=15.388 & X 1+11.210 X_{2}+0.067 X_{3}-5.032 X_{1}^{2}-1.744 X_{2}^{2} \\
& -1.32 X_{1} X_{2}-0.012 X_{1} X_{3}-0.008 X_{2} X_{3}\end{array}$ & 0.999 & 0.846 & 767 \\
\hline
\end{tabular}

Table 4. Calculated silica nanoparticles and BTCA coated fabric properties using regression equations.

\begin{tabular}{|c|c|c|c|c|c|c|c|c|c|c|c|c|c|c|c|c|}
\hline \multirow[t]{2}{*}{$\begin{array}{l}\text { Sample } \\
\text { No. }\end{array}$} & \multirow{2}{*}{$\begin{array}{c}\text { Nano } \\
\text { silica } \\
\%\end{array}$} & \multirow[t]{2}{*}{$\mathrm{PH}$} & \multirow[t]{2}{*}{$\begin{array}{c}\text { Curing } \\
\text { time }\end{array}$} & \multicolumn{2}{|c|}{$\begin{array}{l}\text { Crease recovery } \\
\text { angle }(w+f)\end{array}$} & \multicolumn{2}{|c|}{$\begin{array}{l}\text { Whiteness } \\
\text { index }\end{array}$} & \multicolumn{2}{|c|}{$\begin{array}{l}\text { Tensile } \\
\text { strength }\end{array}$} & \multicolumn{2}{|c|}{$\begin{array}{l}\text { Tear } \\
\text { strength }\end{array}$} & \multirow{2}{*}{$\begin{array}{l}\text { Flexural } \\
\text { rigidity } \\
\text { mg.cm }{ }^{-1}\end{array}$} & \multirow{2}{*}{$\begin{array}{l}\text { Weight } \\
\text { loss } \\
\text { in } \%\end{array}$} & \multirow{2}{*}{$\begin{array}{c}\text { Air } \\
\text { permeability } \\
\text { in } \mathrm{cm}^{3} \cdot \mathrm{cm}^{-2} / \mathrm{s}\end{array}$} & \multirow[t]{2}{*}{$\begin{array}{l}\text { Quality } \\
\text { factor }\end{array}$} & \multirow[t]{2}{*}{ Rank } \\
\hline & & & & Degrees & $\begin{array}{c}\text { Increase } \\
\text { in } \%\end{array}$ & WI & $\begin{array}{c}\text { Retention } \\
\%\end{array}$ & $\mathrm{~kg}$ & $\begin{array}{c}\text { Increase } \\
\text { in } \%\end{array}$ & $\mathrm{~g}$ & $\begin{array}{c}\text { Increase } \\
\text { in } \%\end{array}$ & & & & & \\
\hline 1 & 2 & 3.01 & 180 & 226 & 140.43 & 69.24 & 84.23 & 70.74 & 22.81 & 1410 & 7.47 & 1918 & 1.95 & 24.05 & 427.6 & 5 \\
\hline 2 & 2 & 3.01 & 60 & 223 & 137.23 & 70.44 & 85.69 & 92.35 & 60.33 & 1451 & 10.59 & 1909 & 1.59 & 21.78 & 433.1 & 1 \\
\hline 3 & 2 & 3.01 & 120 & 222 & 136.17 & 69.84 & 84.96 & 85.14 & 47.81 & 1448 & 10.37 & 1914 & 1.77 & 22.91 & 431.9 & 2 \\
\hline 4 & 2 & 1.52 & 180 & 204 & 117.02 & 66.97 & 81.47 & 67.77 & 17.66 & 1403 & 6.94 & 1894 & 2.72 & 25.2 & 417.1 & 14 \\
\hline 5 & 2 & 1.52 & 60 & 200 & 112.77 & 68.17 & 82.93 & 86.7 & 50.52 & 1374 & 4.73 & 1885 & 2.54 & 21.5 & 414.8 & 15 \\
\hline 6 & 2 & 1.52 & 120 & 202 & 114.89 & 67.57 & 82.20 & 80.83 & 40.33 & 1407 & 7.24 & 1890 & 2.63 & 23.35 & 418.4 & 13 \\
\hline 7 & 2 & 2.39 & 180 & 218 & 131.91 & 68.29 & 83.08 & 71.04 & 23.33 & 1439 & 9.68 & 1908 & 2.17 & 25.47 & 427.1 & 6 \\
\hline 8 & 2 & 2.39 & 60 & 218 & 131.91 & 69.49 & 84.54 & 91.54 & 58.92 & 1451 & 10.59 & 1899 & 1.89 & 22.6 & 430.4 & 4 \\
\hline 9 & 2 & 2.39 & 120 & 218 & 131.91 & 68.89 & 83.81 & 84.89 & 47.38 & 1463 & 11.51 & 1904 & 2.03 & 24.03 & 431.1 & 3 \\
\hline 10 & 1.5 & 3.01 & 180 & 215 & 128.72 & 70.74 & 86.06 & 64.75 & 12.41 & 1424 & 8.54 & 1875 & 2.39 & 28.23 & 421.2 & 10 \\
\hline 11 & 1.5 & 3.01 & 60 & 214 & 127.66 & 71.94 & 87.52 & 84.69 & 47.03 & 1434 & 9.30 & 1866 & 1.67 & 25.24 & 423.9 & 8 \\
\hline 12 & 1.5 & 3.01 & 120 & 214 & 127.66 & 71.34 & 86.79 & 78.32 & 35.97 & 1447 & 10.29 & 1870 & 2.03 & 26.73 & 424.7 & 7 \\
\hline 13 & 1.5 & 1.52 & 180 & 196 & 108.51 & 68.47 & 83.30 & 60.4 & 4.86 & 1375 & 4.80 & 1851 & 2.98 & 28.39 & 407.1 & 16 \\
\hline 14 & 1.5 & 1.52 & 60 & 187 & 98.94 & 69.67 & 84.76 & 77.65 & 34.81 & 1316 & 0.30 & 1842 & 2.44 & 23.97 & 400.0 & 23 \\
\hline 15 & 1.5 & 1.52 & 120 & 192 & 104.26 & 69.07 & 84.03 & 72.63 & 26.09 & 1363 & 3.89 & 1846 & 2.71 & 26.18 & 406.0 & 18 \\
\hline 16 & 1.5 & 2.39 & 120 & 210 & 123.40 & 70.4 & 85.64 & 64.48 & 11.94 & 1445 & 10.14 & 1860 & 2.22 & 27.44 & 420.1 & 11 \\
\hline 17 & 1.5 & 2.39 & 60 & 207 & 120.21 & 71 & 86.37 & 83.3 & 44.62 & 1417 & 8.00 & 1856 & 1.89 & 25.65 & 418.8 & 12 \\
\hline 18 & 1.5 & 2.39 & 180 & 212 & 125.53 & 69.8 & 84.91 & 77.49 & 34.53 & 1436 & 9.45 & 1865 & 2.54 & 29.24 & 422.3 & 9 \\
\hline 19 & 1 & 3.01 & 180 & 200 & 112.77 & 72.25 & 87.90 & 59.5 & 3.30 & 1362 & 3.81 & 1831 & 2.42 & 29.89 & 405.8 & 19 \\
\hline 20 & 1 & 3.01 & 60 & 195 & 107.45 & 73.45 & 89.36 & 73.69 & 27.93 & 1342 & 2.29 & 1822 & 1.33 & 26.18 & 403.3 & 20 \\
\hline 21 & 1 & 3.01 & 120 & 197 & 109.57 & 72.85 & 88.63 & 68.16 & 18.33 & 1370 & 4.42 & 1827 & 1.88 & 28.03 & 406.5 & 17 \\
\hline 22 & 1 & 1.52 & 180 & 179 & 90.43 & 69.97 & 85.12 & 58.52 & 1.60 & 1271 & -3.13 & 1808 & 2.83 & 29.07 & 387.4 & 25 \\
\hline 23 & 1 & 1.52 & 60 & 165 & 75.53 & 71.17 & 86.58 & 65.28 & 13.33 & 1282 & -2.29 & 1799 & 1.92 & 23.93 & 384.1 & 27 \\
\hline 24 & 1 & 1.52 & 120 & 172 & 82.98 & 70.57 & 85.85 & 61.09 & 6.06 & 1275 & -2.82 & 1803 & 2.38 & 26.5 & 385.4 & 26 \\
\hline 25 & 1 & 2.39 & 180 & 196 & 108.51 & 71.3 & 86.74 & 59.26 & 2.88 & 1357 & 3.43 & 1821 & 2.49 & 30.49 & 402.9 & 21 \\
\hline 26 & 1 & 2.39 & 60 & 187 & 98.94 & 72.5 & 88.20 & 71.73 & 24.53 & 1308 & -0.30 & 1813 & 1.48 & 26.18 & 396.2 & 24 \\
\hline 27 & 1 & 2.39 & 120 & 192 & 104.26 & 71.9 & 87.47 & 66.76 & 15.90 & 1350 & 2.90 & 1817 & 1.98 & 28.34 & 401.6 & 22 \\
\hline
\end{tabular}



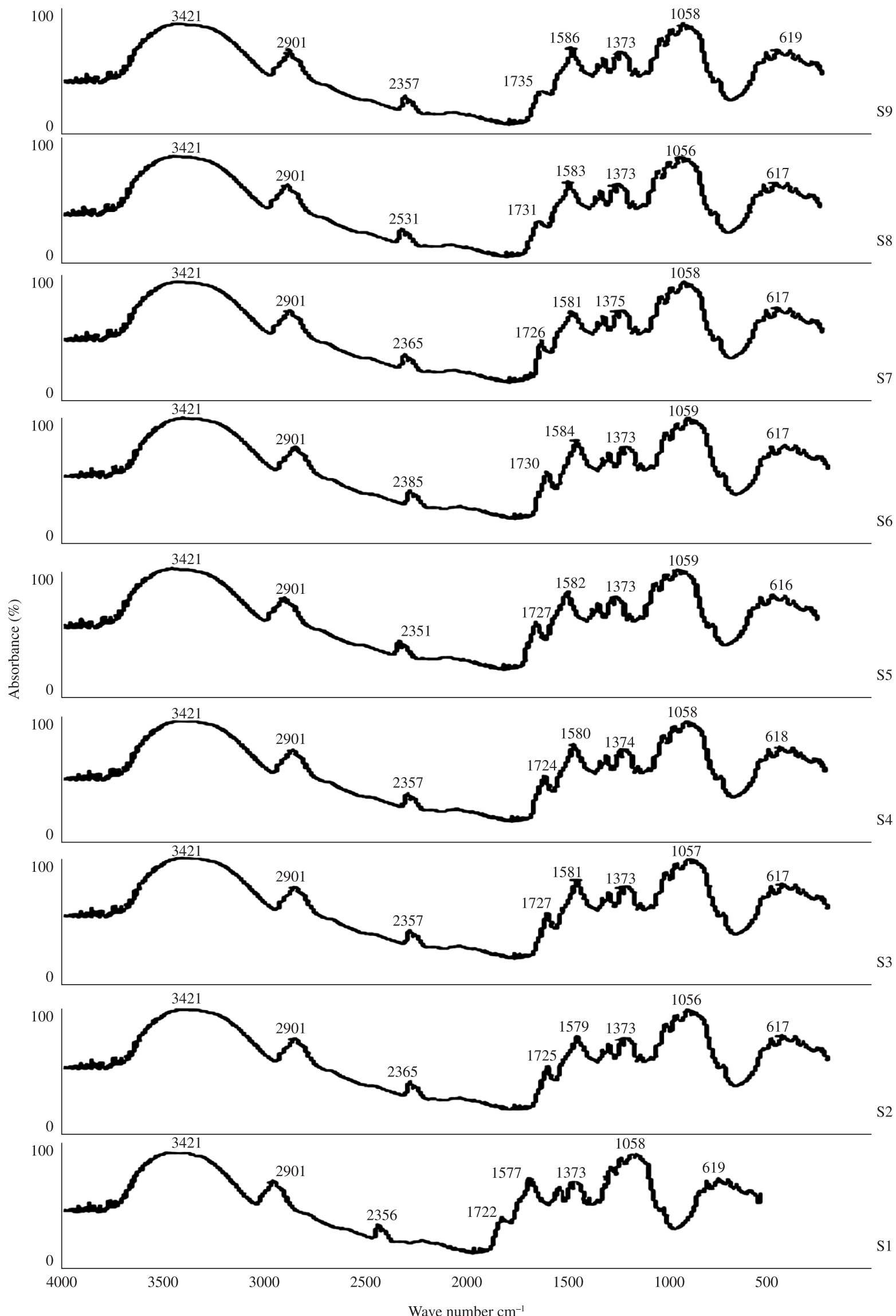

Figure 4. FTIR spectroscopy of silica nanoparticles and BTCA treated fabrics. 


\section{Discussion}

\subsection{Influence of process parameters on crease recovery angle}

Nanometregrade metal oxides such as $\mathrm{TiO}_{2}, \mathrm{Ag}, \mathrm{MgCl}_{2}, \mathrm{SiO}_{2}$ and $\mathrm{ZrO}_{2}$ are used as a co-catalyst along with non formaldehyde cross linking agents to improve the crease recovery properties of cotton fabric ${ }^{25}$. As the particle size of the $\mathrm{TiO}_{2}$ is in nano-scale, the nano $\mathrm{TiO}_{2}$ could fill the amorphous region of the $\mathrm{CellOH}$, and hence, the presence of nano $\mathrm{TiO}_{2}$ inside the fibre would probably restrict the molecular movement of cellulose ${ }^{25}$.

Silica nanoparticles intrude more easily into the interior of cotton fibre and adhere more tightly to the fibre structure ${ }^{21}$. It was observed that, the increase of concentration of silica nanoparticles contributes more to increase the crease recovery angle of the fabric due to restriction of the molecular movement in the fibre structure than $\mathrm{pH}$. During the curing process, the polycarboxylic acid reacts with the cellulose molecules of cotton fabric most probably through the formation of cyclic anhydrides as reactive intermediates, which, in turn, esterify cotton cellulose. Due to increase of ester carbonyl band intensity ratio while increasing the $\mathrm{pH}$ from 1.52 to 3.01 , the crease recovery property has also been increased ${ }^{17}$. The increase in curing time increased the crease recovery angle due to the formation of more esterification of cellulose and the Figure 5 shows its contribution is minimum when compared to silica nanoparticles and $\mathrm{pH}$.

\subsection{Influence of process parameters on whiteness index}

Citric acid is one of the nonformaldehyde cross linking agents, the cotton fabric yellowing caused by citric acid at elevated temperatures and the yellowness increases as curing temperature, curing time, and CA concentration increase. Using sodium hypophosphite as a catalyst causes less fabric yellowing than monosodium phosphate. Therefore, yellowing caused by citric acid and other hydroxyl multi functional carboxylic acids can probably be attributed to the formation of unsaturated polycarboxylic acids ${ }^{26}$.

High acidity of chemicals is a source of causing fabric tendering and yellowing ${ }^{27}$, hence the $\mathrm{pH}$ increases the acidity level reduces and the whiteness of the fabric has been increased and it is shown in Figure 6. The increase in curing time and silica nanoparticles concentration gradually reduces the whiteness index of the fabric. The reduction of whiteness index up to $19 \%$ is due to higher concentration of silica nanoparticles, higher curing time and lower $\mathrm{pH}$.

\subsection{Influence of process parameters on tensile strength}

Cross linking between cellulose molecules causes stiffening of the cellulosic macromolecular network and fibre embrittlement, thus reducing the mechanical strength of the treated cotton ${ }^{28}$. The increase in $\mathrm{pH}$ improves the tensile strength of the fabric due to its decrease of acidic nature of the solution. The acidity of the cross linking treatment had a severe effect on the reduction of strength of the treated cotton fabrics and trapping of nano metal oxide particles

Table 5. Influence of curing time and $\mathrm{pH}$ on ester carbonyl intensity and carbonyl band intensity ratio of Silica nanoparticles and BTCA treated fabric.

\begin{tabular}{|c|c|c|c|c|c|c|c|c|c|}
\hline Samples & S1 & $\mathrm{S} 2$ & S3 & S4 & S5 & S6 & S7 & S8 & S9 \\
\hline $\mathrm{pH}$ & & 1.52 & & & 2.39 & & & 3.01 & \\
\hline Curing time & 60 & 120 & 180 & 60 & 120 & 180 & 60 & 120 & 180 \\
\hline Ester carbonyl band intensity & 0.516 & 0.519 & 0.524 & 0.527 & 0.529 & 0.532 & 0.536 & 0.540 & 0.545 \\
\hline Carbonyl band intensity ratio (Ester/Carboxylate) & 0.619 & 0.623 & 0.626 & 0.610 & 0.612 & 0.615 & 0.629 & 0.632 & 0.636 \\
\hline
\end{tabular}

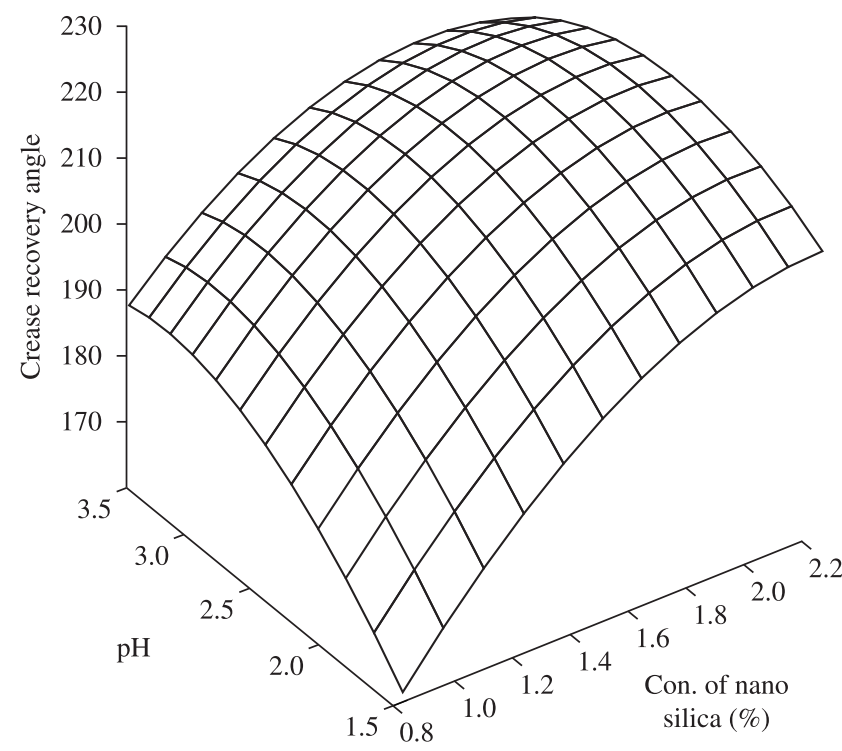

(a)

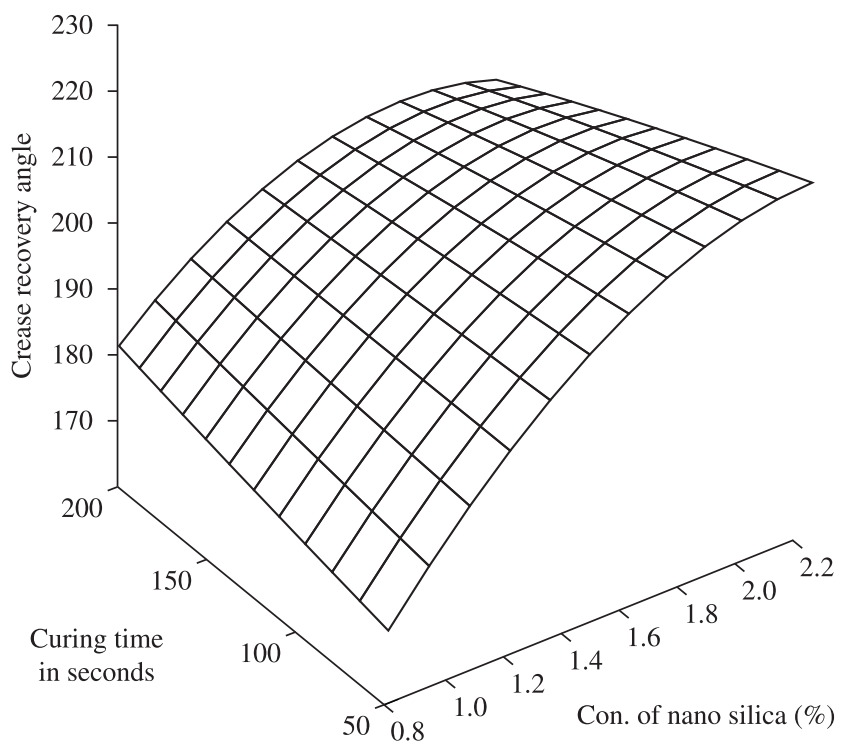

(b)

Figure 5. Influence of silica nanoparticles, $\mathrm{pH}$ and curing time on crease recovery angle. 


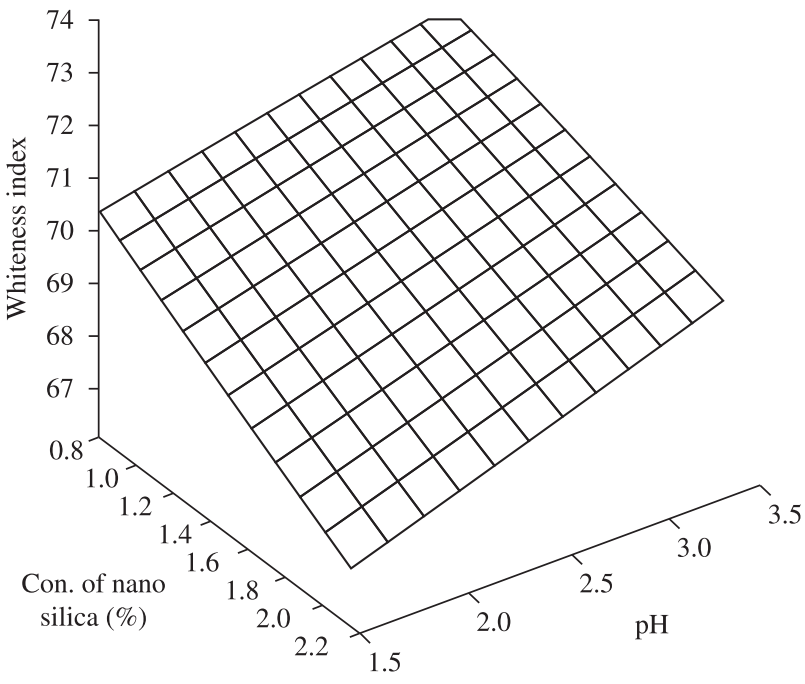

(a)

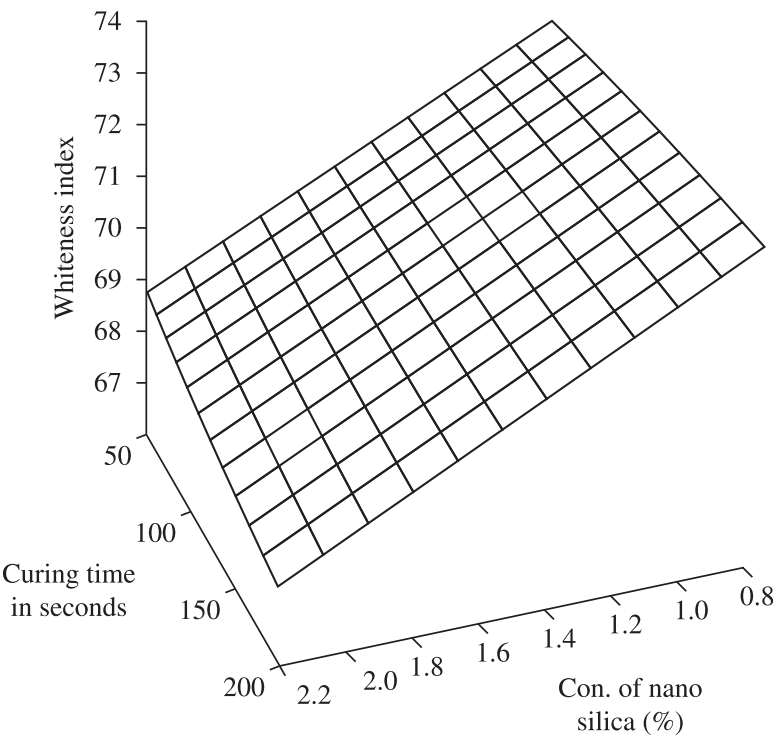

(b)

Figure 6. Influence of silica nanoparticles, $\mathrm{pH}$ and curing time on whiteness index.

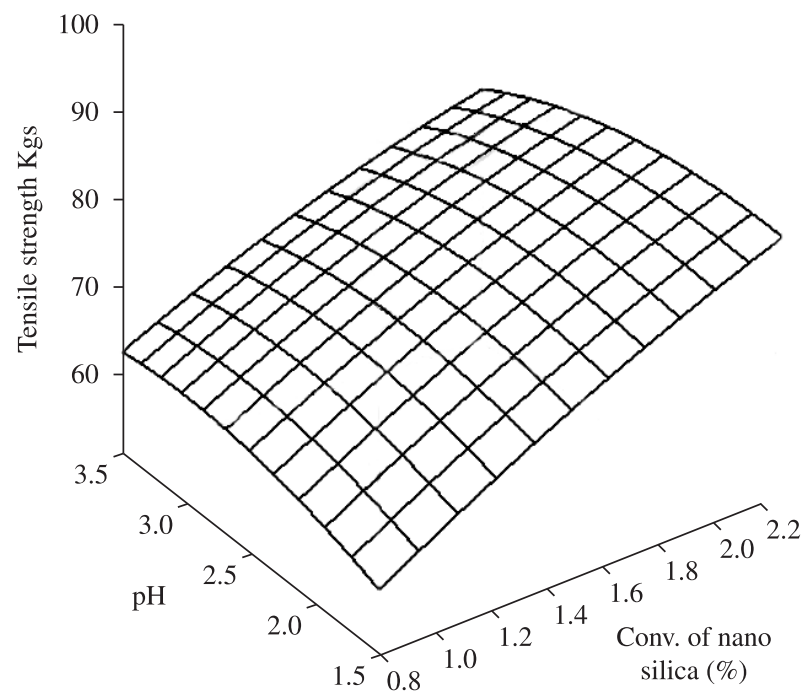

(a)

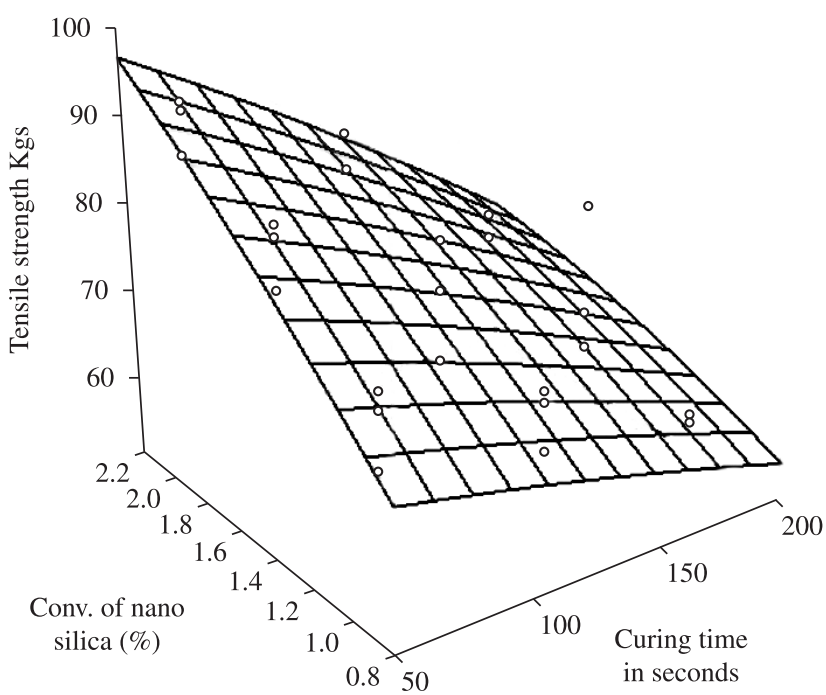

(b)

Figure 7. Influence of Silica nanoparticles, $\mathrm{pH}$ and curing time on tensile strength.

improves the strength of the fabric ${ }^{27}$. Hence, the higher concentration of nano metal oxides results increases the strength of the cotton fabric and it is shown in Figure 7 The increase of curing time reduced the tensile strength of fabric due to more esterification (acid dehydration at high temperatures and high curing time) and cross linking, when it was treated with BTCA/SHP. The same trend has been followed for tear strength.

The investigated process parameters showed insignificant effect on properties such as flexural rigidity, weight loss due to abrasion and air permeability

\section{Conclusions}

The silica nanoparticles were synthesized by thermal degradation method from natural resource such as rice hull and the particles are amorphous in nature with the size of 50 to $100 \mathrm{~nm}$. Silica nanoparticles particles along with optimized concentration of
BTCA of $6.5 \%$ as a cross linking agent and optimized concentration of SHP of $4.5 \%$ as a catalyst were applied on the cotton fabric as per the experimental plan. The BTCA and SHP accelerates the esterification of cellulose to form more number of cross links between the molecules. The effect of curing time and $\mathrm{pH}$ on ester carbonyl intensity ratio has been studied and the ester carbonyl intensity ratio significantly increases while increasing the $\mathrm{pH}$ value and curing time. The combination of crosslinking of cellulose and trapping of nano silica particles significantly increases the crease recovery angle of the fabric. The higher $\mathrm{pH}$ level and lower curing time significantly retains the whiteness index of the fabric, since the curing process contributes maximum to reduce the whiteness index of the fabric. The tensile strength of the fabric was significantly increased due to the intreraction of nano silica with cotton fibres and other process parameters. The weight loss of the fabric was increased in the range of 1.33 to $2.83 \%$. The influence of the process parameters on flexural 
rigidity and air permeability characteristics of the fabric was observed. There is no significant difference and specific trend. The concentration of silica nanoparticles of $2 \%, \mathrm{pH}$ of 3.01 and curing time of 60 seconds observed as best combination to impart crease recovery finish. The Fourier Transform Infra Red spectrometer (FTIR) studies revealed that the formation of ester carbonyl band and carboxylate band intensity ratio. Both were increased by increasing the $\mathrm{pH}$ vale from 1.52 to 3.01 and the curing time from 60 to 180 seconds. The increased crease recovery angle of the fabric is due to the formation of more cross links, silica nanoparticles trapping and also noticed that the increase in ester carbonyl intensity from 0.516 to 0.547 and carboxylate band intensity ratio from 0.619 to 0.637 .

\section{References}

1. Saravanan D. Functional finishing of garments An Overview. Asian Dyer. 2007; 43-51.

2. Michal Werner Schmitt and Yoram Benjamin. Small particles for high performance-nano technology in textile finishing. Asian Textile Journal. 2008; 17(3):39-41.

3. Wong YWH, Yuen CWM, Leung MYS, Ku SKA. and Lam HLI. Selected applications of nanotechnology in textiles. AUTEX Research Journal. 2008; 6(1):1-8.

4. Textor T, Schröer F and Schollmeyer E. Functionalisation of textiles with nanotechnology. Materials Research Society Symposium Proceedings. 2006; 920:0920-S01-02.

5. Patel BH. and Chattopadhyay DP. Nano - particles and their uses in textiles. Asian Dyer. 2008; 53-58.

6. Yang CQ and Wang X. Formation of Cyclic Anhydride Intermediates and Esterification of Cotton Cellulose by Multifunctional Carboxylic Acids: An Infrared Spectroscopy Study. Textile Research Journal. 1996; 66(9):595-603. http://dx.doi.org/10.1177/004051759606600908

7. Xiaohong G and Yang CQ. FTIR Spectroscopy Study of the Formation of Cyclic Anhydride Intermediates of Polycarboxylic Acids Catalyzed by Sodium Hypophosphite. Textile Research Journal. 2000; 70(1):64-70. http://dx.doi.org/10.1177/004051750007000110

8. Yang CQ. FT-IR Spectroscopy Study of the Ester Crosslinking Mechanism of cotton Cellulose. Textile Research Journal. 1991; 61(8):433-440. http:// dx.doi.org/10.1177/004051759106100801

9. Brodmann GL. Performance of Nonformaldehyde Cellulose Reactants. AATCC Review.1990; 22(11):13-16.

10. Xu W and Li Y. Cotton Fabric Strength Loss from Treatment with Polycarboxylic Acids for Durable Press Performance. Textile Research Journal. 2000; 70(11):957-961. http://dx.doi. org/10.1177/004051750007001104

11. Bilgen M, Hauser P and Smith B. Ionic crosslinking of cellulose. Indian Journal of Fibre and Textile Research. 2006; 31(3):363-368

12. Franklin WE, Madacsi J and Rowland SP. Recurable Durable-Press Fabrics Part III: Textile, Chemical, and Recuring Properties of Fabrics Treated with DMDHEU and Polycarboxylic Acids. Textile Research Journal. 1973; 43(6):361-366. http://dx.doi.org/10.1177/004051757304300609

13. Franklin WE, Madacsi JP and Rowland SP. Recurable Durable-Press Fabrics Part I: Polycarboxylic Acids as Coreactant Curing Catalysts with N-Methylol Reagents. Textile Research Journal. 1972; 43(6):274-280.
14. Franklin WE, Madacsi JP and Rowland SP. Recurable Durable-Press Fabrics Part II: Recurability of Fabrics Treated with Methylol Reagents and Polycarboxylic Acids. Textile Research Journal. 1972; 42(9):553-557. http://dx.doi.org/10.1177/004051757204200907

15. Schramm C, Binder WH and Tessadri R. Durable Press Finishing of Cotton Fabric with 1,2,3,4-Butanetetracarboxylic Acid and TEOS/GPTMS. Journal of Sol-Gel Science and Technology. 2004; 29(3):155-165. http:// dx.doi.org/10.1023/B:JSST.0000023850.97771.7d

16. Yang CQ. Effect of $\mathrm{pH}$ on Non-formaldehyde durable press finishing of cotton fabric: FTIR spectroscopy study. Textile Research Journal. 1993; 63(12):706-711. http://dx.doi.org/10.1177/004051759306301202

17. Yang CQ. Effect of $\mathrm{pH}$ on Non-formaldehyde durable press finishing of cotton fabric : FTIR spectroscopy study. Textile Research Journal. 1993; 63(7):420-430. http://dx.doi.org/10.1177/004051759306300707

18. Alterman DS. and Chun KW. Encapsulated particles. 1978. Patent US4142734.

19. Wang S, Hou W, Wei L, Jia H, Liu X and Xu B. Antibacterial activity of nano-SiO2 antibacterial agent grafted on wool surface. Surface and Coating Technology. 2007; 202(3):460-473. http://dx.doi.org/10.1016/j. surfcoat.2007.06.012

20. Yuranova T, Mosteo R, Bandara J, Laub T and Kiwi J. Photocatalytic Discoloration of Organic Compounds on Outdoor Building Cement Panels Modified by SiO2-TiO2 Photoactive Coatings. Journal of Molecular Catalysis A: Chemical. 2006; 244(1):160-168. http://dx.doi.org/10.1016/j. molcata.2005.08.059

21. Li F, Xing Y and Ding X. Silica Xerogel Coating on the surface of natural and synthetic fabrics. Surface and Coating Technology. 2008; 202(19):4721-4727. http://dx.doi.org/10.1016/j.surfcoat.2008.04.048

22. Jasiorski M, Bakardijeva S, Doroszkiewicz W, Brzeziński S, Malinowska G, Marcinkowska D et al. Properties and applications of silica Submicron powders with surface Ag nanoclusters. Materials Science-Poland. 2004; 22(2):137-144

23. Huang KS, Nien YH, Hsiao KC. and Chang YS. Application of DMEU/ $\mathrm{SiO}_{2}$ Gel solution in the antiwrinkle finishing of cotton fabrics. Journal of Applied Polymer Science. 2006; 102(5):4136-4143. http://dx.doi. org/10.1002/app.24246

24. Kalapathy U, Proctor A and Shultz J. An improved method for production of silica from rice hull ash', Bio-resource Technology. 2000; 85(3):285289. http://dx.doi.org/10.1016/S0960-8524(02)00116-5

25. Yuen CWM, Ku SKA, Li Y, Cheng YF, Kan CW, Choi PSR. Improvement of wrinkle-resistant treatment by nanotechnology. Journal of The Textile Institute. 2009; 100(2):173-180. http://dx.doi. org/10.1080/00405000701661028

26. Lu Y and Yang CQ. Fabric Yellowing Caused by Citric Acid as a Crosslinking Agent for Cotton. Textile Research Journal. 1999; 69(9):685-690. http://dx.doi.org/10.1177/004051759906900909

27. YL Lam, CW Kan and CWM Yuen. Wrinkle-resistant finishing of cotton fabric with BTCA - the effect of co-catalyst. Textile Research Journal. 81(5):482-493. http://dx.doi.org/10.1177/0040517510380777

28. Charles Qixiang Yang, Weishu Wei and Lickfield G.C. Mechanical Strength of durable Press finished cotton Fabric. Textile Research Journal. 2000; 70(2):143-147. http://dx.doi.org/10.1177/004051750007000209 